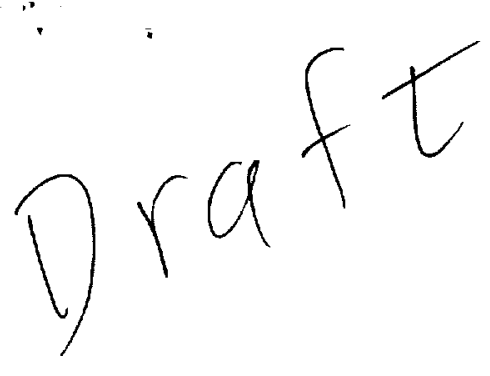

\title{
X33 Transient Liftoff Analysis
}

\author{
Jeff Peck* and Joseph Brunty $\dagger$ \\ Structural Dynamics and Loads Group/ED21 \\ Structures, Mechanics, and Thermal Department \\ NASA/Marshall Space Flight Center \\ Huntsville, AL 35812
}

\begin{abstract}
$\underline{\text { Abstract }}$
The successful design of a launch vehicle requires the careful characterization of the various loads the structure will experience over its lifetime. Many of the most demanding load environments occur during the launch/ascent phase of a mission, typically defined as the point of engine start through engine cut off. One of the critical events during the launch phase is the liftoff event. This event imparts high loads on the vehicle due to transient events such as thrust build-up and vehicle release. This paper describes the theory and procedures used to calculate structural loads due to the liftoff event for the Lockheed-Martin X33 technology demonstrator vehicle. These procedures were developed at NASA's Marshall Space Flight Center and verified previously on other advanced launch system concepts and the Space Shuttle system.
\end{abstract}

\section{Introduction}

The liftoff event is one of the most extreme operating environments for launch vehicles and related ground support equipment. Typically, thrust structures, hold-down structures and launch pads experience their maximum loads during this event. Also, other structures may be highly loaded due to secondary effects such as overpressure and acoustics (the analysis described here does not consider acoustics). The severity of the liftoff event is due, in part, to the typical way that vertical take-off vehicles are launched. Generally, vertical take-off vehicles are held firmly to the launch pad until the engines have reached a thrust level sufficient for liftoff. Many launch vehicles, including the X33, are bolted to the pad with large "holddown" bolts. These bolts are normally under significant tension loads when the engines reached their liftoff thrust

*Aerospace Technologist, Structural Dynamics

†Aerospace Technologist, Structural Dynamics; Member AIAA

Copyright $\theta 2000$ by the American Institute of Aeronautics and Astronautics. Inc. No copyright is asserted in the United States under Title 17, U.S. Code. The U.S. government has a royalty-free license to exercise all rights under the copyright claimed herein for Governmental purposes. All other rights are reserved by the copyright owner. level. At the time of release, small explosives are detonated in the hold-down bolt nuts (called frangible nuts), which rapidly releases the bolt tension, and therefor the vehicle. This causes a large shock load to both the launch vehicle and the launch pad resulting in high dynamic loads within each structure.

The liftoff analysis of the $\mathrm{X} 33$ vehicle uses a methodology developed at Marshall Space Flight Center during the mid 80 's. A basic explanation of the theory is presented later in this paper, and a full description is contained in reference 1. In general, the method allows separate linear models to be analyzed as a coupled system until a specified release time. At the time of release, the coupling constraints are relaxed (very rapidly) and the models are free to behave as separate structures. The use of linear models allows efficient computations and reduces non-linear modeling complexities.

\section{$\underline{\text { Models }}$}

\section{Vehicle}

The vehicle model for the $\mathrm{X} 33$ transient liftoff analysis is a MSC/NASTRAN finite element model constructed for use in loads and dynamic analysis. The vehicle was divided into several sections for model construction, with different individuals of the X33 team responsible for each section. Assembly and integration of the full vehicle model was performed at MSFC. Because of the general nature of this model, it is too large for a transient analysis in its base (unreduced) form. The table below lists the model sizes.

\begin{tabular}{|l|l|l|}
\hline & Vehicle (w/100\% fuel) & RLM \\
\hline Grids & 20556 & 258 \\
\hline Elements & 32611 & 385 \\
\hline Weight (lbs) & 297,320 & 68,342 \\
\hline Modes to 35 Hz & 979 & 4 \\
\hline
\end{tabular}

Component modal synthesis (Craig Bampton reduction) was used to reduce the model to a manageable size. This was done within MSC/NASTRAN using their superelement methodology. The boundary degrees of freedom (DOF's) used for the reduction of the vehicle model were the four grids that represent the interface to the launch pad (i.e. the hold-down points). Using MSC terminology, the 24 DOF's represented by these grids were used as the boundary degrees

1 
of freedom (i.e. the b-set) for the vehicle superelement. All other grids in the vehicle model were considered internal to the vehicle superelement. Figure 1 shows the vehicle model coupled with the launch pad, while figure 2 shows the vehicle model with part of the upper Thermal Protection System (TPS) removed to expose the internal structure.

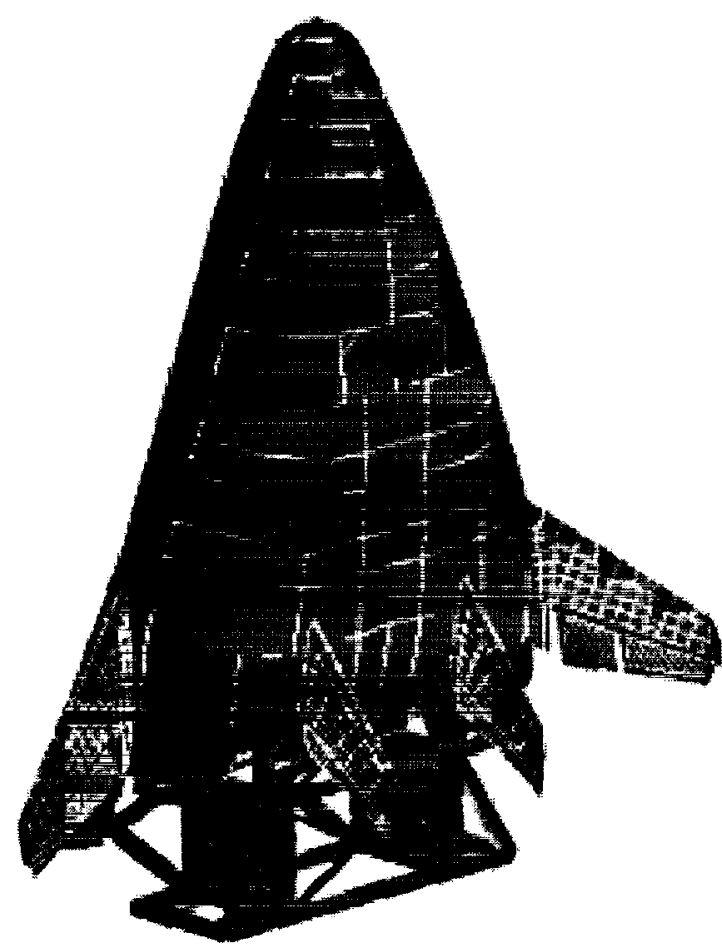

Figure 1. Coupled vehicle and pad models

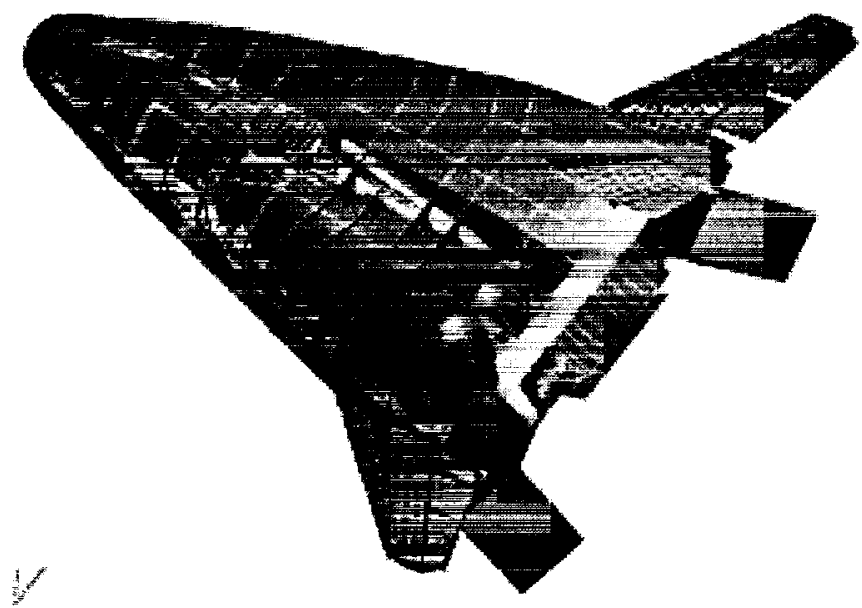

Figure 2. Vehicle model cut-away

The Lancoz modal extraction method was used to calculate component modes up to $35 \mathrm{~Hz}$. The reduced liftoff model with $100 \%$ fuel weighed in at 1003 degrees of freedom as extracted from MSC/NASTRAN (24 boundaries and 979 modes).

\section{Launch Pad}

The model of the launch pad was also constructed as a MSC/NASTRAN finite element model. The X33 launch pad is also called the rotating launch mount (RLM) because it is used to rotate the vehicle from a horizontal service position to the vertical launch position. The loads model for the RLM is a relatively simple steel structure constructed mostly of bar and plate elements, with concentrated masses representing the various non-structural systems. Table 1 includes the basic statistics of the RLM model while figure 3 shows a plot of the structure.

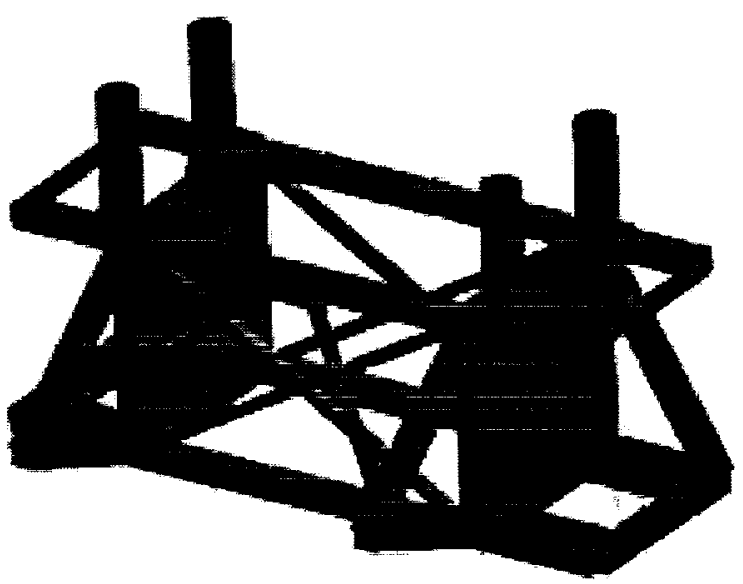

Figure 3. Rotating Launch Mount

\section{Hydroelastic Modeling of LOX}

One of the most challenging aspects in the finite element modeling of rocket launch vehicles is the modeling of the propellant. The propellant represents approximately $73 \%$ of the total weight of the $X 33$ launch vehicle at liftoff of which $85 \%$ is LOX weight. Not only is it important that this is represented, but it is very important to capture the physical dynamics of the interaction of the propellant fluid with the tank structure. During the liftoff transient event the interaction of the LOX fluid with the tank structure, especially the bulkhead, can be a significant driver for loads on the tanks and supporting structure. For the X33 vehicle it was even more of a difficult task, because of the geometry of the LOX tank (Figure 4). The LOX fluid for the X33 was modeled by Lockheed-Martin using the finite element method and the code HYDRO. This code was developed by Martin-Marietta for NASA's Space Shuttle External Tank ${ }^{2}$. It essentially uses the method of weighted residuals to discretise the fluid field as derived from structural mechanics principles. 


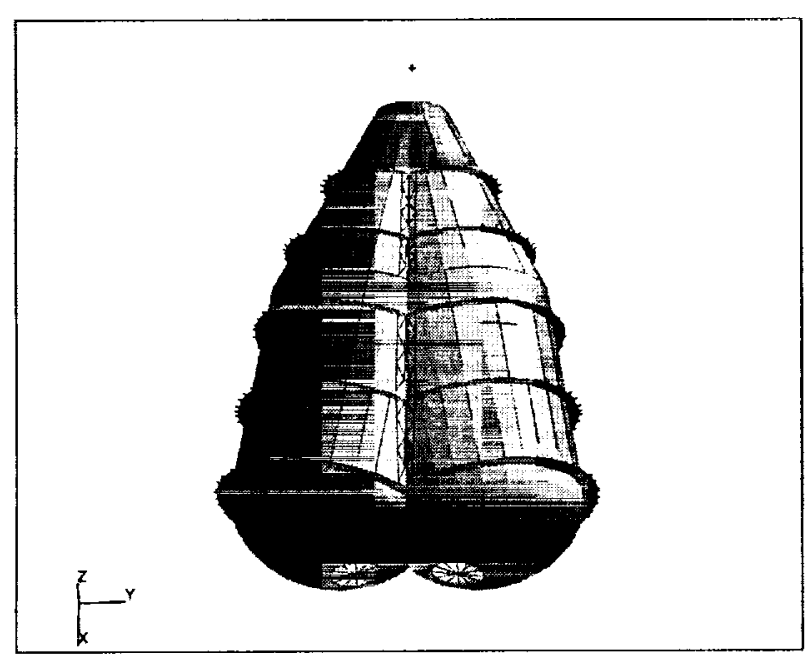

Figure 4. Lox Tank FE model

The resulting fluid equations are then transformed into structural degrees of freedom of the wetted wall of the tank and the free surface of the fluid. The equations are then coupled to the tank structural finite element model. The fluid free surface and tank undergoing the first two slosh modes are shown in figure 5 .

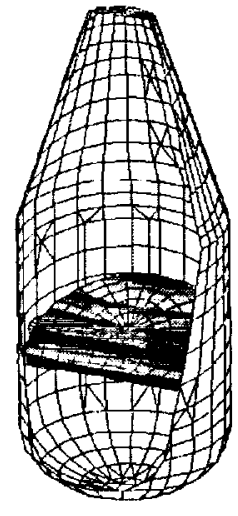

Yaw Mode $0.5978 \mathrm{~Hz}$

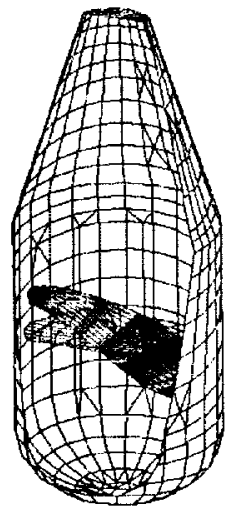

Pitch Mode $0.5354 \mathrm{~Hz}$
Figure 5. LOX tank lobe with slosh modes

\section{Loading Conditions}

There is one secondary and four primary load sources considered for the X33 liftoff analysis. These are overpressure, gravity, wind, thrust, and release timing. Although release timing is not an actual load (technically, a changing boundary condition), it is a load inducing parameter, and is varied as a load for this analysis. Table 2 (included at the end of this document) lists the various load cases for the cycle 5 (C5) liftoff load set. These load cases varied the winds, fuel levels (gravity load), and release timing in and attempt to capture the "worst case" loads. Note that the winds and fuel levels did not change during each transient analysis. Also, the time histories for the transient loads of thrust and overpressure were the same for all cases. The time history trace of thrust power level is plotted in figure 6 .

The secondary load, overpressure, is also applied as a transient force. Overpressure is considered a secondary load since it results from wave reflections off of the flame trench due to sudden changes in the thrust. Figure 7 illustrates the origin of the overpressure load.

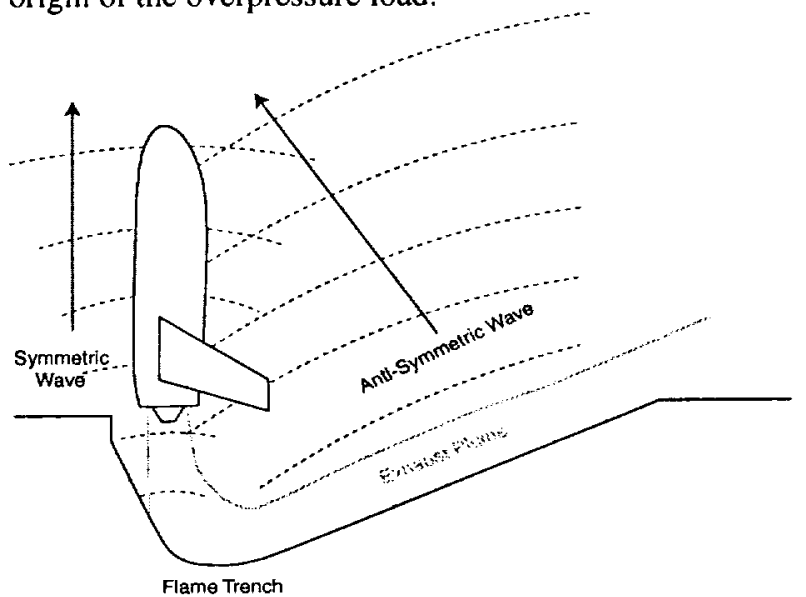

Figure 7. Overpressure source illustration

As shown in figure 7 , there are two components of the overpressure load, identified here as symmetric and antisymmetric. The symmetric component impinges on both sides of the vehicle, while the anti-symmetric wave is applied to the top of the vehicle only. The pressure loads resulting from these traveling waves are applied to the vehicle by sectioning the outer surface into a finite set of discrete bands, or stations, as shown in Figure 8.

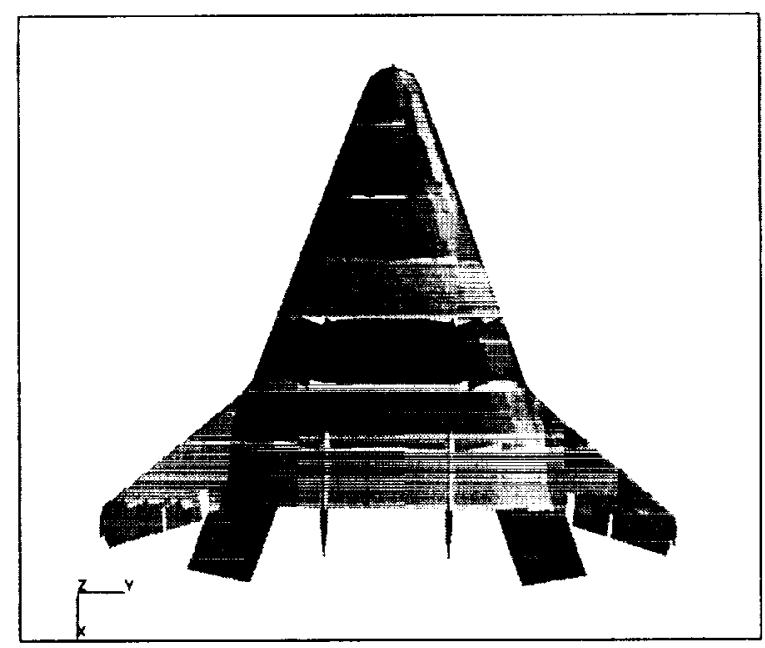

Figure 8. Overpressure stations 
Each station is approximately 100 inches wide (top to bottom) and is associated with a separate unit pressure load set. To simulate the overpressure waves traveling up the vehicle, each overpressure load set is scaled with a pressure time history, delayed with respect to the station below it. The time history traces are shown in figures 9 and 10 . These traces were calculated by the MSFC's unsteady flow group based on principles found in reference [2] and [3]. Since the overpressure loads are dependent on the thrust start-up transient (figure 6), any change in the thrust curve requires a re-calculation of the overpressure curves.

\section{Analysis Theory}

The liftoff transient response methodology used in this analysis was taken from reference 1 . The equations of motion for the launch vehicle and launch platform can be written as:

$$
\begin{aligned}
& {\left[\mathrm{M}_{V}\right]\left\{\ddot{\mathrm{x}}_{V}\right\}+\left[\mathrm{C}_{V}\right]\left\{\dot{\mathrm{x}}_{V}\right\}+\left[\mathrm{K}_{V}\right]\left\{\mathrm{x}_{V}\right\}=\left\{\mathrm{f}_{V}\right\}+\left\{\mathrm{f}_{\mathrm{I}}\right\}} \\
& {\left[\mathrm{M}_{\mathrm{P}}\right]\left\{\ddot{\mathrm{x}}_{\mathrm{P}}\right\}+\left[\mathrm{C}_{\mathrm{P}}\right]\left\{\dot{\mathrm{x}}_{\mathrm{P}}\right\}+\left[\mathrm{K}_{\mathrm{P}}\right]\left\{\mathrm{x}_{\mathrm{P}}\right\}=\left\{\mathrm{f}_{\mathrm{P}}\right\}-\left\{\mathrm{f}_{\mathrm{i}}\right\}}
\end{aligned}
$$

The interface forces between the launch platform and the launch vehicle $\left\{f_{\mathrm{f}}\right\}$ can be represented by a power series approximation with unknown coefficients (keeping only three terms).

$$
\begin{array}{r}
\left\{f_{1}\right\}=\left\{g_{0}\right\}+\left\{g_{1}\right\}\left(t-t_{i}\right)+\left\{g_{2}\right\}\left(t-t_{i}\right)^{2}+\left\{g_{3}\right\}\left(t-t_{i}\right)^{3} \\
\text { for } t_{i} \leq t \leq t_{i}+\Delta t
\end{array}
$$

The equations of motion for the vehicle and launch platform (eqn. la and 1b) along with the interface force equation (2) can then be split into two separate equations of motion with separate responses for the vehicle and launch platform.

$$
\begin{aligned}
{\left[\mathrm{M}_{\mathrm{V}}\right]\left\{\ddot{\mathrm{x}}_{\mathrm{v} 1}\right\}+\left[\mathrm{C}_{\mathrm{V}}\right]\left\{\dot{\mathrm{x}}_{\mathrm{v} 1}\right\}+\left[\mathrm{K}_{\mathrm{V}}\right]\left\{\mathrm{x}_{\mathrm{v} 1}\right\}=\left\{\mathrm{f}_{\mathrm{v}}\right\}+\left\{\mathrm{g}_{0}\right\} } \\
{\left[\mathrm{M}_{\mathrm{V}}\right]\left\{\ddot{\mathrm{x}}_{\mathrm{v} 2}\right\}+\left[\mathrm{C}_{\mathrm{V}}\right]\left\{\dot{\mathrm{x}}_{\mathrm{v} 2}\right\}+\left[\mathrm{K}_{\mathrm{V}}\right]\left\{\mathrm{x}_{\mathrm{v} 2}\right\}=} \\
\left\{\mathrm{g}_{1}\right\}\left(\mathrm{t}-\mathrm{t}_{\mathrm{i}}\right)+\left\{\mathrm{g}_{2}\right\}\left(\mathrm{t}-\mathrm{t}_{\mathrm{i}}\right)^{2}+\left\{\mathrm{g}_{3}\right\}\left(\mathrm{t}-\mathrm{t}_{\mathrm{i}}\right)^{3} \\
{\left[\mathrm{M}_{\mathrm{P}}\right]\left\{\ddot{\mathrm{x}}_{\mathrm{P} 1}\right\}+\left[\mathrm{C}_{\mathrm{P}}\right]\left\{\dot{\mathrm{x}}_{\mathrm{P} 1}\right\}+\left[\mathrm{K}_{\mathrm{P}}\right]\left\{\mathrm{x}_{\mathrm{P} 1}\right\}=\left\{\mathrm{f}_{\mathrm{P}}\right\}-\left\{\mathrm{g}_{0}\right\} } \\
{\left[\mathrm{M}_{\mathrm{P}}\right]\left\{\ddot{\mathrm{x}}_{\mathrm{P} 2}\right\}+\left[\mathrm{C}_{\mathrm{P}}\right]\left\{\dot{\mathrm{x}}_{\mathrm{P} 2}\right\}+\left[\mathrm{K}_{\mathrm{P}}\right]\left\{\mathrm{x}_{\mathrm{P} 2}\right\}=} \\
-\left\{\mathrm{g}_{1}\right\}\left(\mathrm{t}-\mathrm{t}_{\mathrm{i}}\right)-\left\{\mathrm{g}_{2}\right\}\left(\mathrm{t}-\mathrm{t}_{\mathrm{i}}\right)^{2}-\left\{\mathrm{g}_{3}\right)\left(\mathrm{t}-\mathrm{t}_{\mathrm{i}}\right)^{3}
\end{aligned}
$$

Where $\left\{x_{v}\right\}=\left\{x_{v 1}\right\}+\left\{x_{v 2}\right\}$ and $\left\{x_{p}\right\}=\left\{x_{p 1}\right\}+\left\{x_{p 2}\right\}$ along with their derivatives. These equations can then be solved simultaneously using initial conditions and unit loads for the unknown coefficients (g's). By enforcing compatibility at the interfaces and using the responses due to unit loads, a set of equations in terms of the unknown coefficients can be written (see reference 1): $\left\{\begin{array}{l}\mathrm{g}_{1} \\ \mathrm{~g}_{2} \\ \mathrm{~g}_{3}\end{array}\right\}=[\mathrm{C}]^{-1}\left\{\begin{array}{l}\mathrm{d} \\ \dot{d} \\ \ddot{\mathrm{d}}\end{array}\right\}$

Solving for the unknown coefficients at each time step and substituting into equation (2) the interface forces can be computed at that time step. The separation of the vehicle from the launch pad is performed by modifying the terms in the compatibility matrix [C] in equation (5) for those degrees of freedom that are released as the hold down bolts are released.

\section{Analysis Procedure}

The response analysis is performed using a set of FORTRAN programs based on the equations and procedures described in the previous section'. Performing the analysis is done in four basic steps:

1) Extract raw data from NASTRAN

2) Translate to FORMA format

3) Perform analysis initialization

4) Perform response analysis

Further details on each of these steps are described below.

Since the model was constructed in MSC/NASTRAN, the model and related data must be translated into a format usable by the FORTRAN programs. A custom DMAP alter for SOL 112 outputs the needed information to output 2 and output 4 files using a two step process. The first step performs a NASTRAN "cold start" in which the model (vehicle or RLM) component modes are calculated and the mass, stiffness and load matrices are output. The cold start creates the NASTRAN database files with the reduced superelement and associated transformation matrices, and is used for restarts in all subsequent runs. The second step generates the LTMs for data recovery. Restarting from the previously generated database, an identity matrix is passed to the NASTRAN data recovery routines as a dummy response matrix. The results from the data recovery routines are LTMs which, when post-multiplied by actual response vectors, generate the output responses requested in the case control section. In order to keep the LTM size to manageable levels; response requests are generally broken up into several sets. This requires multiple restart runs, since only one "FORCE" and "DISPLACEMENT" request may be made for each NASTRAN analysis. The resulting files contain the matrices:

$$
\left[\mathrm{M}_{\mathrm{aa}}\right],\left[\mathrm{K}_{\mathrm{aa}}\right],\left[\mathrm{P}_{\mathrm{a}}\right],\left[\mathrm{TATM}_{\mathrm{xa}}\right],\left[\mathrm{TEF}_{\mathrm{ya}}\right]
$$

Here the subscripts indicate the row and column dimension, where " $a$ " is the size of the NASTRAN a-set, " $\mathrm{n}$ " is the number of requested displacements, and " $y$ " is the number of requested element forces. Note that the load matrix is 
actually composed of column vectors, each of which corresponds to a NASTRAN load set (gravity, wind, etc...). In the actual response analysis, these vectors will be scaled with time history traces to generate the required time varying loads.

The files from the NASTRAN runs with the SOL 112 alter are read by the FORTARN program Stepl. This program performs some basic checks on the NASTRAN raw data, and translates the data into FORMA ${ }^{*}$ binary files. The step 1 program also creates DOF maps for the model and LTM matrices.

An analysis initialization program reads the results from the step 1 program and performs a final series of modifications before the response analysis. First, the rotational DOF's at the vehicle and RLM boundaries are not needed since the interface is assumed to be "pinned". To accommodate this assumption, another CMS reduction is performed with the rotational DOF's of the boundaries as interior DOF's. Second, normal modes of the model are calculated and the equations are translated to un-coupled equations in generalized coordinates. In this format, it is easy to create a modal damping matrix by simply specifying the modal damping factors. A modal damping factor of $0.5 \%$ was used for the C5 loads analysis. Finally, the initialization program modifies the LTM'S for compatibility with the generalized coordinates and calculates the initial conditions and interface forces. This information is written out to a file for processing by the response run. The resulting matrices are;

$$
\begin{aligned}
& {\left[\mathrm{M}_{\mathrm{qq}}\right]=[\mathrm{I}]=[\Phi]^{\mathrm{T}}\left[\mathrm{M}_{\mathrm{aa}}\right][\Phi]} \\
& {\left[\mathrm{C}_{\mathrm{qq}}\right]=[\mathrm{I}]\left\{2 \xi_{\mathrm{i}} \omega_{\mathrm{i}}\right\}} \\
& {\left[\mathrm{K}_{\mathrm{qq}}\right]=[\mathrm{I}]\left\{\omega_{\mathrm{i}}^{2}\right\}=[\Phi]^{\mathrm{T}}\left[\mathrm{K}_{\mathrm{aa}}\right][\Phi]} \\
& {\left[\mathrm{P}_{\mathrm{q}}\right]=[\Phi]^{\mathrm{T}}\left[\mathrm{P}_{\mathrm{a}}\right]} \\
& {\left[\mathrm{TATM}_{\mathrm{xq}}\right]=\left[\mathrm{TATM}_{\mathrm{xa}}\right][\Phi]} \\
& {\left[\operatorname{TEF}_{\mathrm{yq}}\right]=\left[\mathrm{TEF}_{\mathrm{ya}}\right][\Phi]}
\end{aligned}
$$

Where " $q$ " indicates the generalized coordinates, and the mode vectors are mass normalized.

The response analysis program reads the un-coupled models, applied forces, and initial conditions generated by the initialization program, and executes the time step analysis. As the response run progresses, the physical interface forces are written to the standard output file. A sample plot of the interface forces for load set L05508 is shown in figure 11. These forces are helpful for checking that the analysis is

\footnotetext{
* FORMA stands for FORtran Matrix Analysis, and is a library of FORTRAN routines and originally developed for Marshall Space Flight Center by the Martin Marietta Corp.
}

starting from the correct conditions and behaving in the expected way. For example, notice that the interface force traces follow the general shape of the thrust build-up curve. Also, the "steady state" condition of the forces during the first part of the plot indicates that the initial conditions were calculated correctly.

The result of the response run is the displacements, velocities and accelerations in generalized coordinates.

\section{Data Recovery}

Because the results from the response analysis are in generalized coordinates, they must be transformed into physical responses (forces, accelerations, etc...) to be of any use. Also, an uncertainty factor of $50 \%$ is added to the dynamic portion of the response during this phase. This is meant to account for inaccuracies in the model, analysis and environmental data. Finally, The loads are sorted and tabulated for distribution.

Adding the 50\% uncertainty factor on the dynamic response is fairly straightforward for accelerations and velocities. Since these values are defined with respect to their rest state of zero, we may add a factor to the dynamic portion of the response by modifying only the responses associated with the elastic modes. Recall from the previous section that the acceleration transformation matrix was modified from its original NASTRAN form such that post multiplying it by the generalized accelerations will yield the physical accelerations requested in the NASTRAN case control section.

$$
\{\ddot{\mathrm{x}}\}=\left[\operatorname{TATM}_{\mathrm{xq}}\right]\{\ddot{q}\}
$$

Using partition notation, equation 6 can be written as

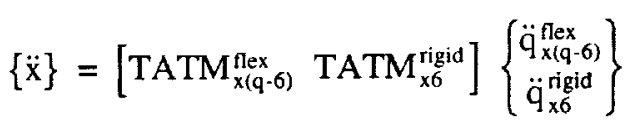

In 7 , the superscript "flex" is used to represent generalized DOF's associated with the elastic modes, while "rigid" indicates DOF's associated with the rigid body modes. Mathematically, it makes no difference weather we multiply the " $q$ " values or the columns of TATM by 1.5 , however, because of the large number of " $q$ " vectors (one for each time step) it is much more efficient to modify the column of the TATM associated with the elastic modes.

Displacements and Element forces require a different technique for adding a factor to the dynamic portion. Instead, first consider the basic dynamic system of equations,

$$
\{\ddot{\mathrm{q}}\}+2\left[\xi_{i} \omega_{i}\right]\{\dot{\mathrm{q}}\}+\left[\omega_{i}^{2}\right]\{\mathrm{q}\}=\mathrm{f}(\mathrm{t})
$$

If we let the inertial and damping force be zero, we have the static equilibrium equation in modal coordinates 


$$
\left[\omega_{i}^{2}\right]\left\{\mathrm{q}_{\text {stat }}\right\}=\mathbf{f}(\mathbf{t})
$$

Then

$$
\left\{\mathrm{q}_{\text {stat }}\right\}=\frac{1}{\left[\omega_{i}^{2}\right]^{\mathrm{f}(\mathrm{t})}}
$$

Where $q$ is defined as the sum of it's static and dynamic components

$$
\{\mathrm{q}\}=\left\{\mathrm{q}_{\text {stat }}\right\}+\left\{\mathrm{q}_{\mathrm{dyn}}\right\}
$$

By defining the new displacements with the uncertainty factor as

$$
\left\{\mathrm{q}_{\text {new }}\right\}=1.5\left\{\mathrm{q}_{\text {dyn }}\right\}+\left\{\mathrm{q}_{\text {stat }}\right\}
$$

and substituting from (11) and then (10)

$$
\begin{aligned}
\left\{\mathrm{q}_{\text {new }}\right\} & =1.5\left\{\mathrm{q}-\mathrm{q}_{\text {stat }}\right\}+\left\{\mathrm{q}_{\text {stat }}\right\} \\
& =1.5\{\mathrm{q}\}-0.5\left\{\mathrm{q}_{\text {stat }}\right\} \\
& =1.5\{\mathrm{q}\}-0.5 \frac{1}{\left[\omega_{i}^{2}\right]} \mathrm{f}(\mathrm{t})
\end{aligned}
$$

Substituting the left side of $(8)$ for $f(t)$ results in an expression dependant only on $\mathrm{q}$

$$
\begin{aligned}
\left\{\mathrm{q}_{\text {new }}\right\} & \left.=1.5\{\mathrm{q}\}-\frac{0.5}{\left[\omega_{i}^{2}\right]}[\ddot{\mathrm{q}}\}+2\left[\xi_{i} \omega_{i}\right]\{\dot{\mathrm{q}}\}+\left[\omega_{i}^{2}\right]\{\mathrm{q}\}\right] \\
& =\{\mathrm{q}\}-\frac{0.5}{\left[\omega_{i}^{2}\right]}\{\ddot{\mathrm{q}}\}-\frac{\left[\xi_{i}\right]}{\left[\omega_{i}\right]}\{\dot{\mathrm{q}}\}
\end{aligned}
$$

Since most launch vehicles are very lightly damped $(0.5 \%$ used for X33), the last term in (14) is generally very small, and is therefore ignored. Then the final form of the equation for adding the uncertainty factor to the modal coordinates is

$$
\left\{\mathrm{q}_{\text {new }}\right\}=\{\mathrm{q}\}-\frac{0.5}{\left[\omega_{i}^{2}\right.}\{\ddot{\mathrm{q}}\}
$$

These new responses can now be used with the appropriate LTM to generate the desired element forces or grid displacements. Figure 12 shows a sample time history and shock spectra plot. These results are for an element force in the thrust structure.

Once the responses have been modified with the uncertainty factor, the time history of each response is scanned for the maximum and minimum values. These values are saved in a table along with their load case ID and time stamp. The individual max-min tables are then scanned by a composite max-min program, which scans the results for all load cases and sorts out the 5 most extreme values ( 5 max and $5 \mathrm{~min}$ ). These values are printed in a table, which lists the response name, response value, load case and time. Table 3 shows the composite max-min table format.

\section{Summary}

As can be seen from the previous sections, calculating loads for the liftoff event with this technique is not a simple matter. The multiple steps, programs, and varied data sources provide the analyst many opportunities for error. Avoiding these errors requires careful examination of the results at each step with a general understanding of how the structure is expected to react. On the positive side, this technique produces important insights into the vertical liftoff environment, and particularly, into the highly dynamic "release" event. Because of the never-ending pursuit of greater performance from lighter structures, accurate characterization of liftoff loads is critical for safe and robust designs.

\section{References}

'Brunty, J.A. (1990), A Transient Response Analysis of the Space Shuttle Vehicle During Liftoff, NASA Technical Memorandum 103505.

2 Prabhakar, A., (1985), Theoretical Basis of Fluid Modeling Program HYDRO, Interoffice Memo, Martin-Marietta 3524-85-254, Michoud, LA.

${ }^{3}$ Broadwell, J.E., Tsu, C.N., (1961), An Analysis of Transient Pressures Due to Rocket Starting in Underground Launchers, Space Technology Laboratories, Inc. Report 7103-0028-MU-000.

${ }^{4}$ Jones, J.H., (1981), Scaling Considerations of the 6.4\% Model Overpressure Data , Systems Dynamics Laboratory, Structural Dynamics Division, MSFC, ED24-81-47. 


\begin{tabular}{|c|c|c|c|c|c|}
\hline $\begin{array}{l}\pi \prod \pi \\
\prod\end{array}$ & 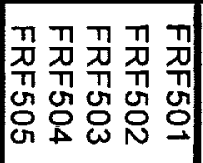 & 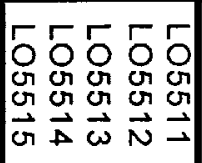 & 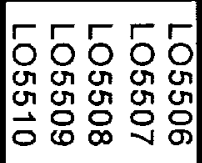 & 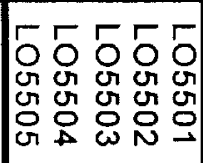 & 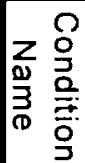 \\
\hline \&ि \&ि \& & 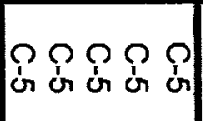 & 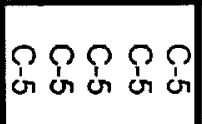 & 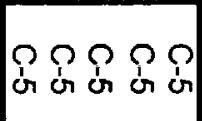 & 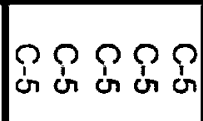 & 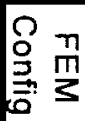 \\
\hline 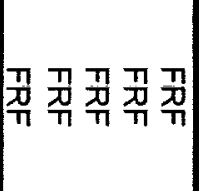 & 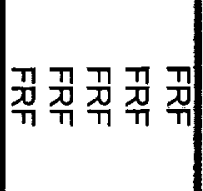 & 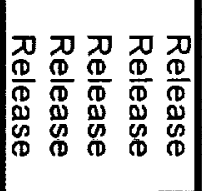 & 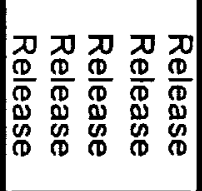 & 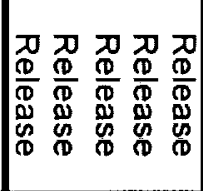 & 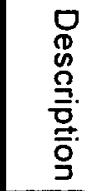 \\
\hline , , , 㷋 , & , , , 岕, & , , , N & 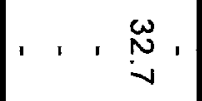 & , , , $\stackrel{N}{N}^{\omega}$, & \begin{tabular}{l|l}
-1 \\
0 \\
0
\end{tabular} \\
\hline , , ${ }^{\omega}$, & , , $\stackrel{\omega}{N}^{\omega}$ & , , & , , $\stackrel{\omega}{N}^{\omega}$, & 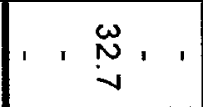 & 塄 \\
\hline , $\stackrel{w}{N},^{w}$, & , $\stackrel{\omega}{N}^{\prime}$, & , $\stackrel{\omega}{N}^{\prime}$, , ' & , $\underline{N}^{\omega}, 1$, & , $\stackrel{\omega}{N}, 1$, & 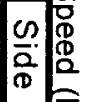 \\
\hline 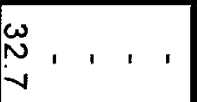 & $\stackrel{\omega}{N}, 1,1$ & $N_{N}^{\omega}, 1,1$ & $\stackrel{\omega}{N}, 1,1$, & $\stackrel{\omega}{\omega}, 1,1$, & 袋 \\
\hline 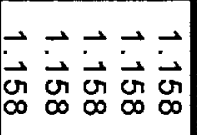 & 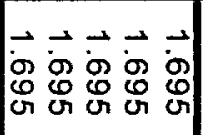 & 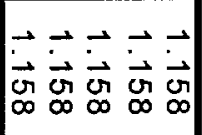 & 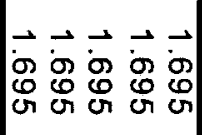 & 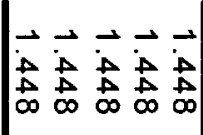 & 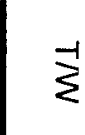 \\
\hline$\frac{Z}{D} \frac{Z}{D} \frac{Z}{D} \frac{Z}{D}$ & $\frac{Z}{D} \frac{Z}{D} \frac{Z}{D} \frac{Z}{D} \frac{Z}{D}$ & 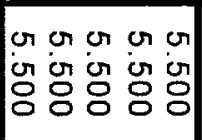 & 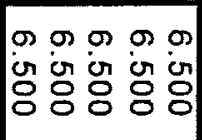 & 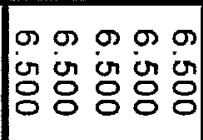 & 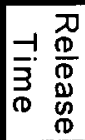 \\
\hline 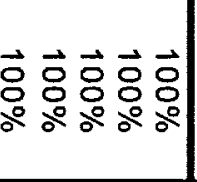 & 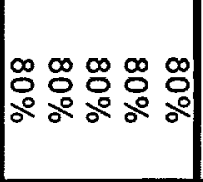 & 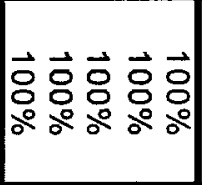 & $\begin{array}{l}\infty \\
0 \\
0 \\
0 \\
0\end{array}$ & 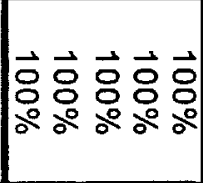 & 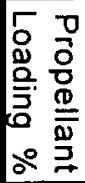 \\
\hline 0 & $\overrightarrow{0} \overrightarrow{0} \overrightarrow{0} \overrightarrow{0} \overrightarrow{0}$ & $\infty \infty^{\infty} \infty$ & $\overline{0} \overline{0} \overline{0} \overline{0}$ & $\overrightarrow{0} \overrightarrow{0} \overrightarrow{0} \overrightarrow{0} \overrightarrow{0}$ & \\
\hline
\end{tabular}

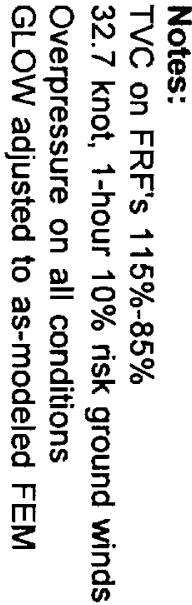

\begin{tabular}{|c|c|c|c|c|c|}
\hline 융 융융ㅇㅇㅇㅇㅇ & 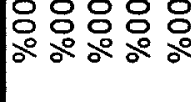 & 융ㅇㅇㅇㅇㅇㅇㅇㅇㅇㅇ & 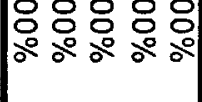 & 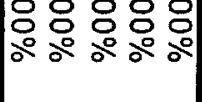 & $\frac{c}{\circ}$ \\
\hline $\begin{array}{lllll}\infty & \infty & \infty & \infty & \infty \\
0 & 0 & 0 & 0 \\
0 & 0 & 0 \\
0 & 0 & 0 & 0 & 0 \\
0 & 0 & 0\end{array}$ & 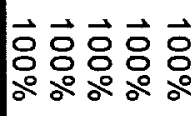 & $\frac{Z}{\Delta} \frac{Z}{D} \frac{Z}{D} \frac{Z}{D}$ & $\frac{Z}{D} \frac{Z}{D} \frac{Z}{D} \frac{Z}{D} \frac{Z}{D}$ & $\frac{Z}{Z} \underset{D}{Z} \frac{Z}{D} \underset{D}{Z} \frac{Z}{D}$ & $\begin{array}{l}0 \\
g \\
\circ\end{array}$ \\
\hline $\begin{array}{lllll}\omega & \omega & \omega & \omega & \omega \\
\omega & \omega & \omega & \omega & \omega \\
\omega & \omega & \omega & \omega & \omega \\
\infty & \infty & 0 & 0 \\
O & O & 0 & 0 \\
N & N & N & N\end{array}$ & 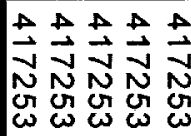 & 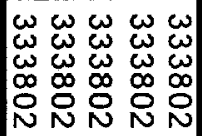 & 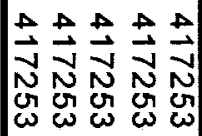 & 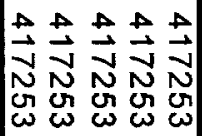 & $\bar{\sigma}$ \\
\hline $\begin{array}{lllll}\omega & \omega & \omega & \omega & \omega \\
N & N & N & N & N \\
0 & 0 & 0 & 0 & 0\end{array}$ & 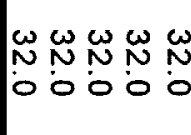 & $\begin{array}{lllll}\omega & \omega & \omega & \omega & \omega \\
N & N & N & N & N \\
0 & 0 & 0 & 0 & 0\end{array}$ & $\begin{array}{lllll}\omega & \omega & \omega & \omega & \omega \\
N & N & N & N & N \\
0 & 0 & 0 & 0 & 0\end{array}$ & 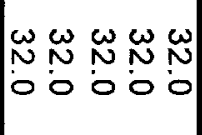 & 怘. \\
\hline $\begin{array}{lllll}\omega & \omega & \omega & \omega & \omega \\
0 & 0 & 0 & 0 & 0 \\
0 & 0 & 0 & 0 & 0\end{array}$ & $\mid \begin{array}{lllll}\omega & \omega & \omega & \omega & \omega \\
0 & 0 & 0 & 0 & 0 \\
0 & 0 & 0 & 0 & 0\end{array}$ & $\begin{array}{lllll}\omega & \omega & \omega & \omega & \omega \\
0 & 0 & 0 & 0 & 0 \\
0 & 0 & 0 & 0 & 0\end{array}$ & $\begin{array}{lllll}\omega & \omega & \omega & \omega & \omega \\
0 & 0 & 0 & 0 & 0 \\
0 & 0 & 0 & 0 & 0\end{array}$ & $\begin{array}{lllll}\omega & \omega & \omega & \omega & \omega \\
0 & 0 & 0 & 0 \\
0 & 0 & 0 & 0 & 0\end{array}$ & 兽. \\
\hline
\end{tabular}



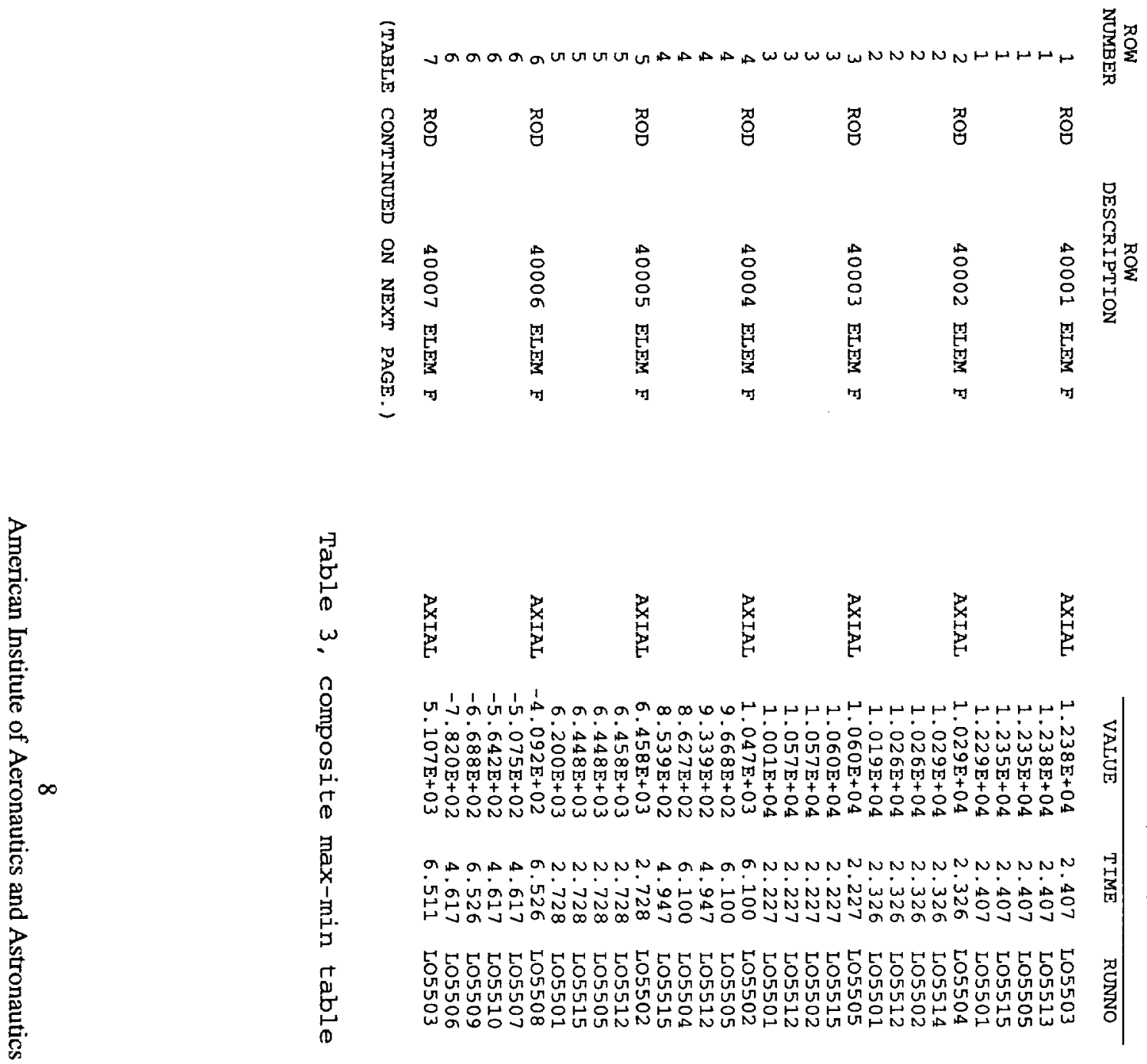

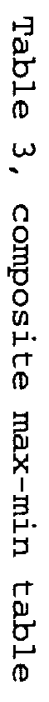
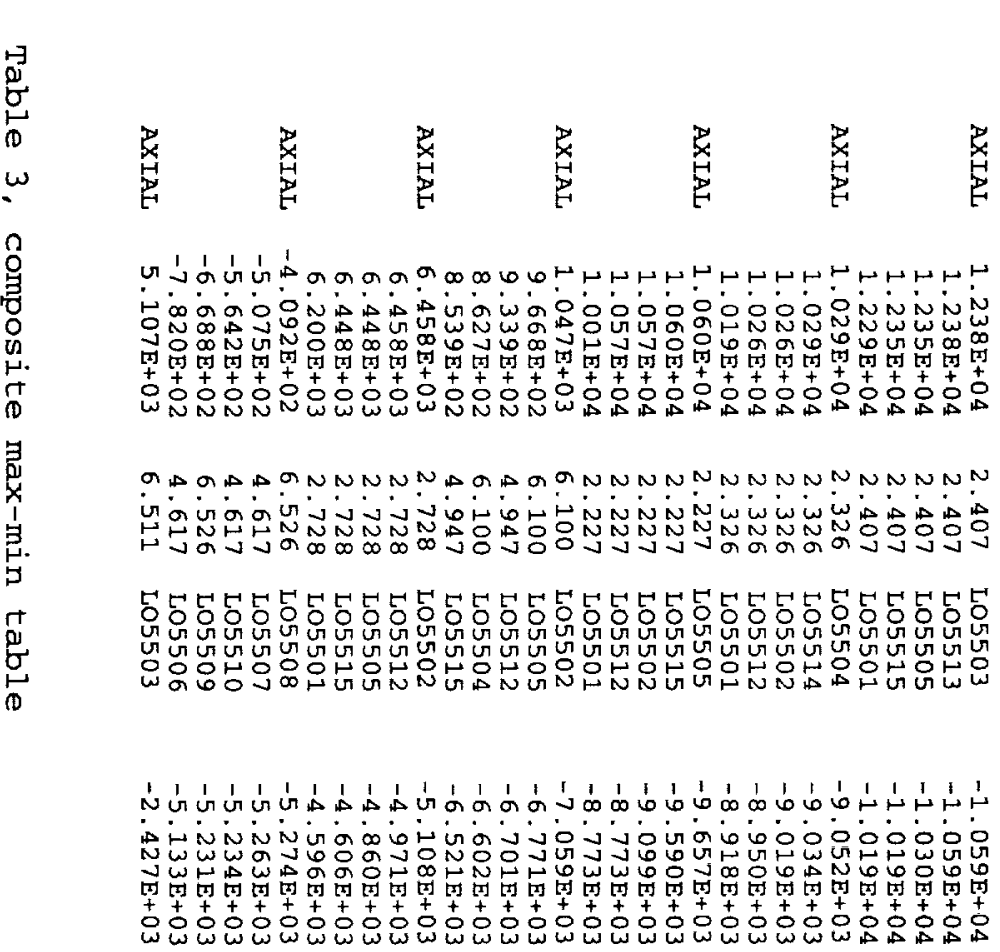

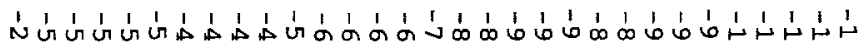

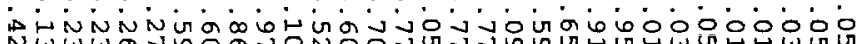

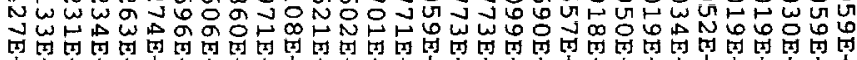
等

NGGGGGNNNNNNNNNNNNNNNNNNNNNNNNN ڤ 
Rev. 5D Engine Start, Nominal Thrust Buildup Profile

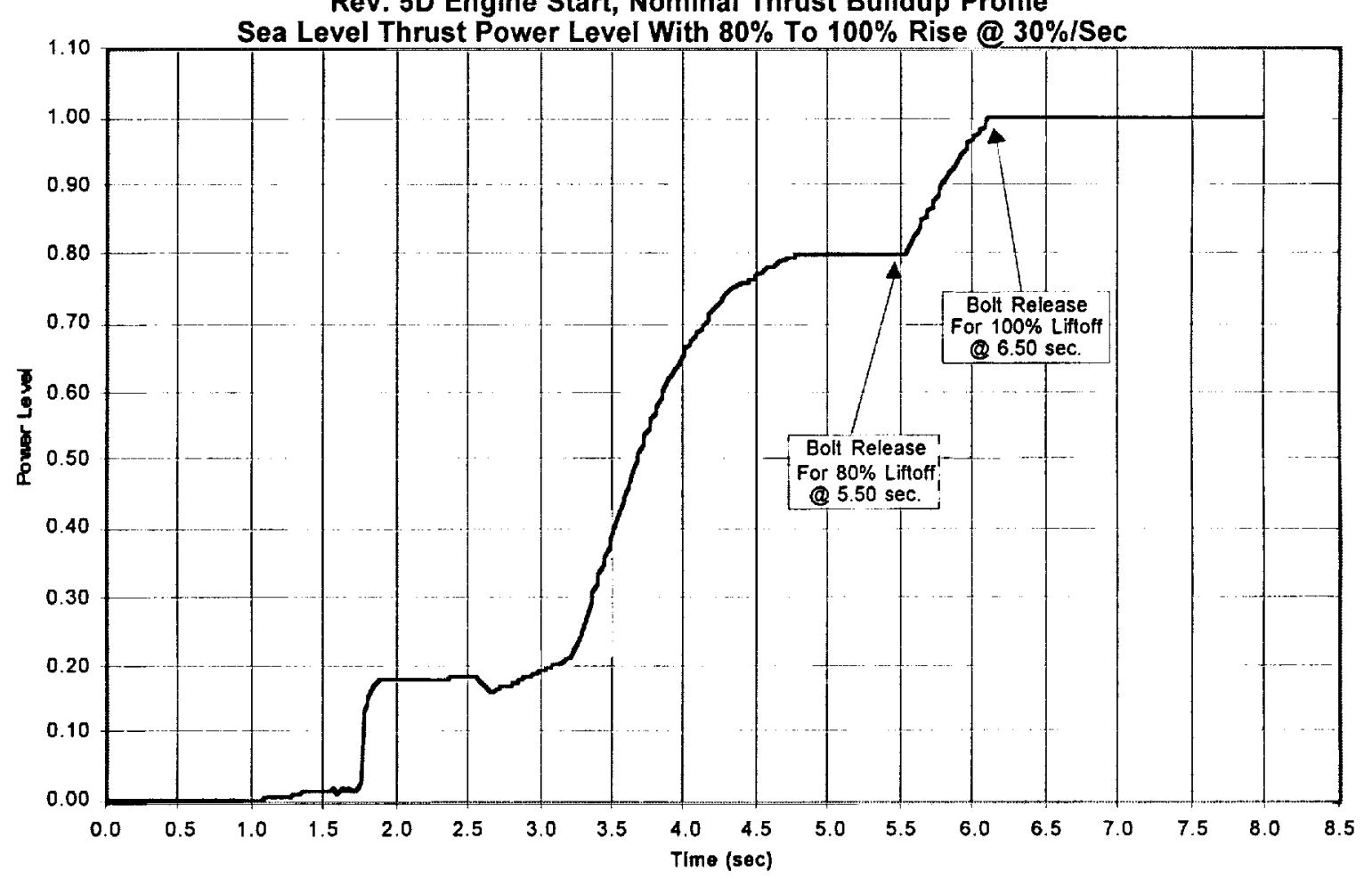

Figure 6. Thrust build-up curve

\section{Overpressure, Symetric}

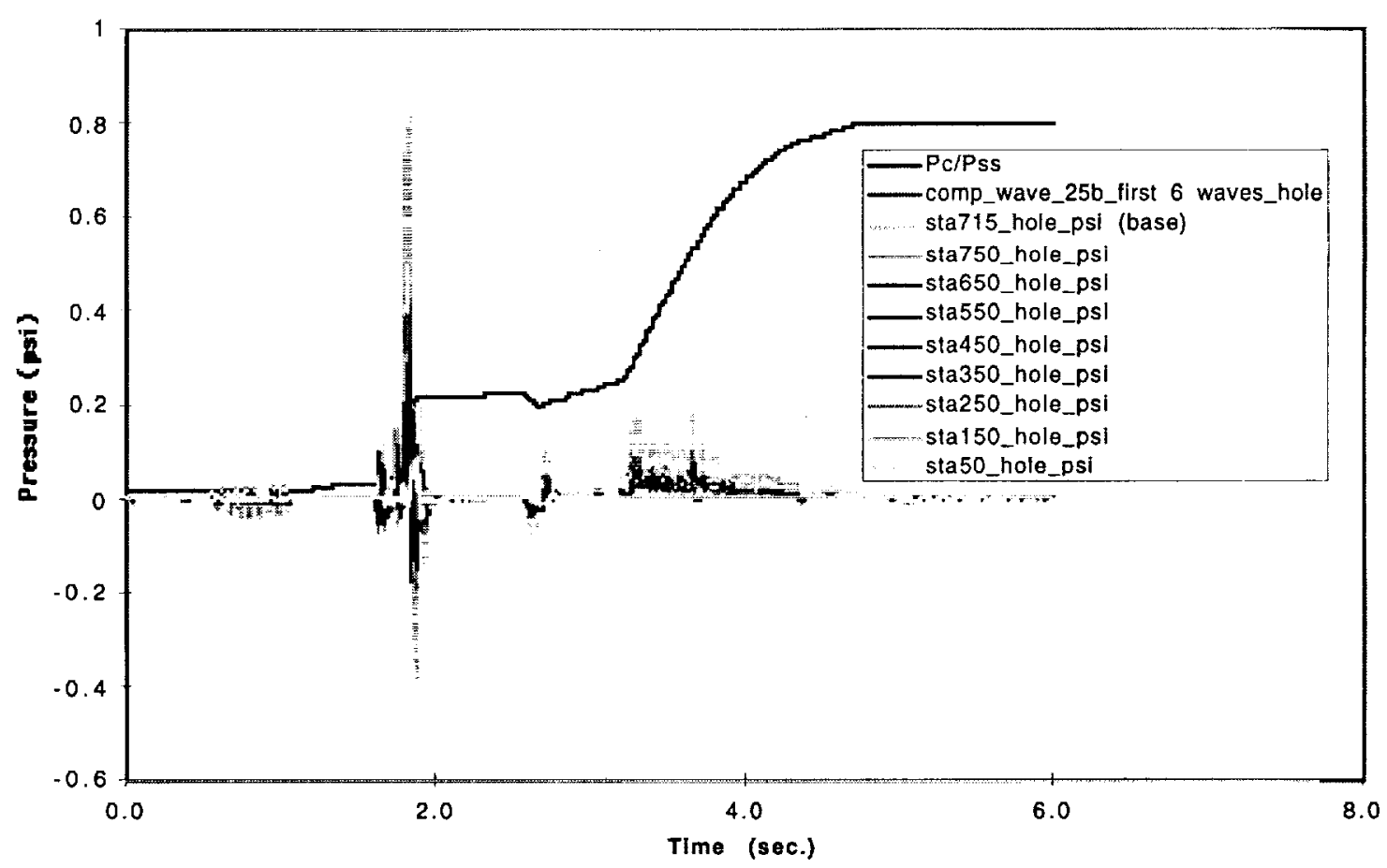

Figure 9. Symmetric overpressure with Pc/Pss (thurst) curve 


\section{Overpressure Anti-Symetric}

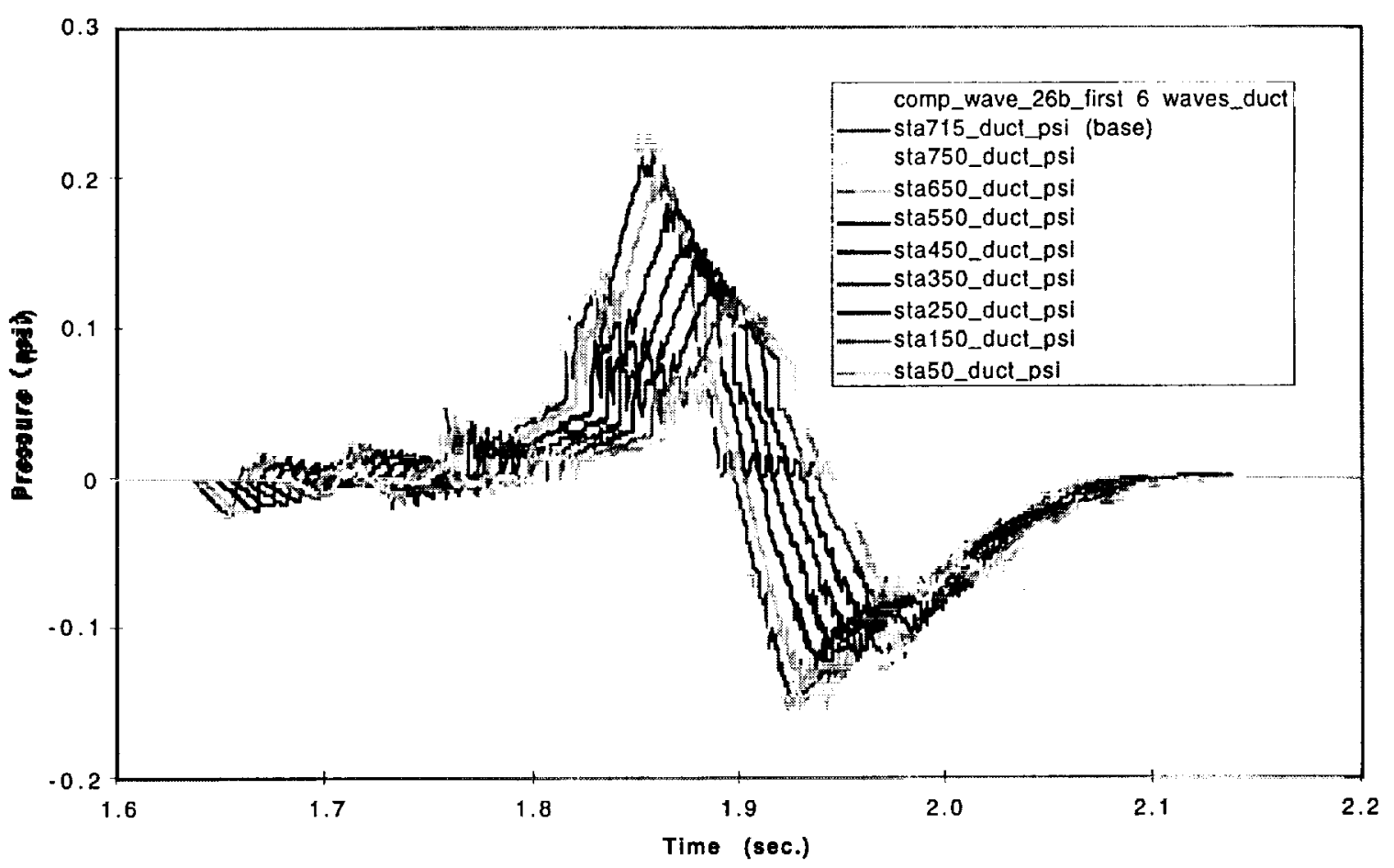

Figure 10. Anti-symmetric overpressure with composite wave

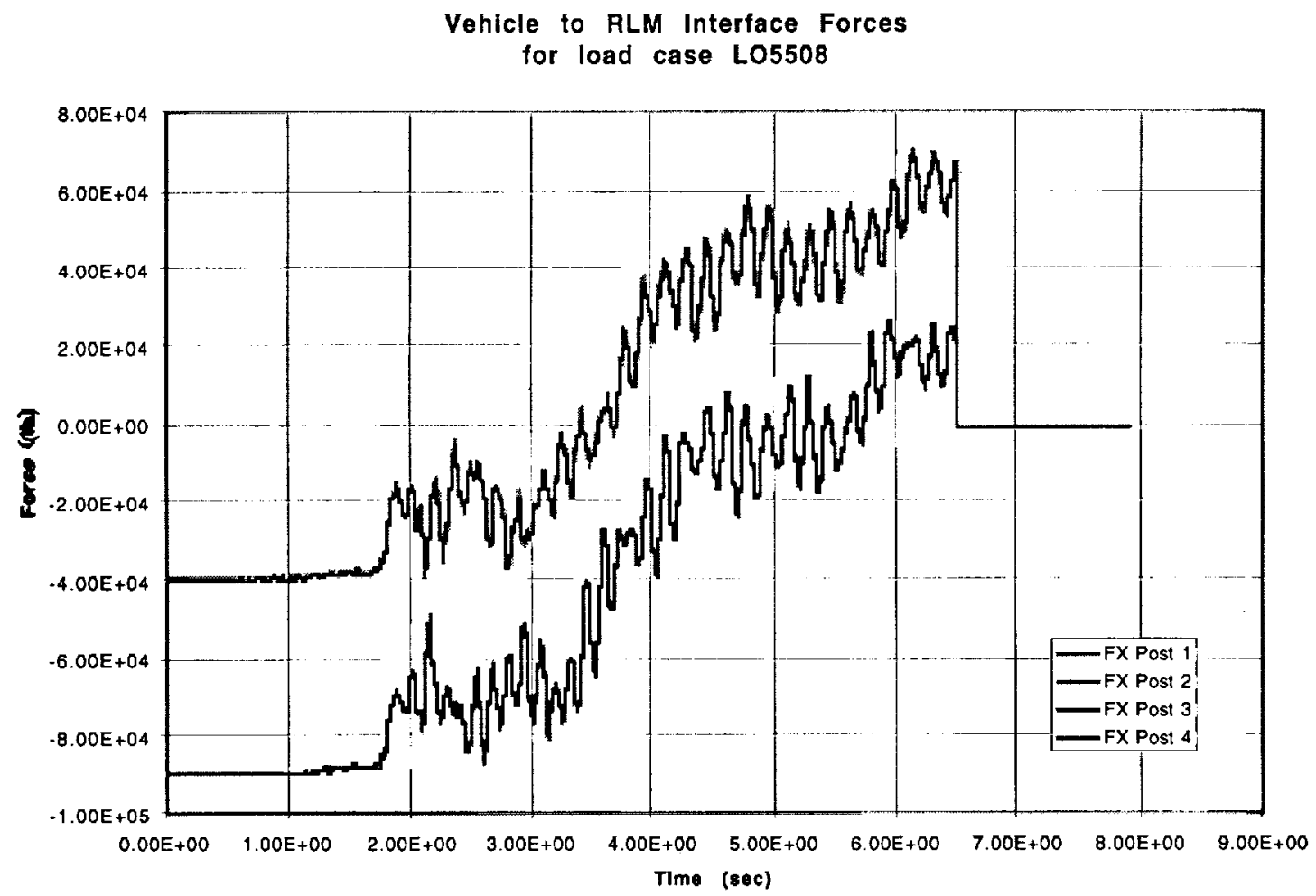

Figure 11, Interface Forces 


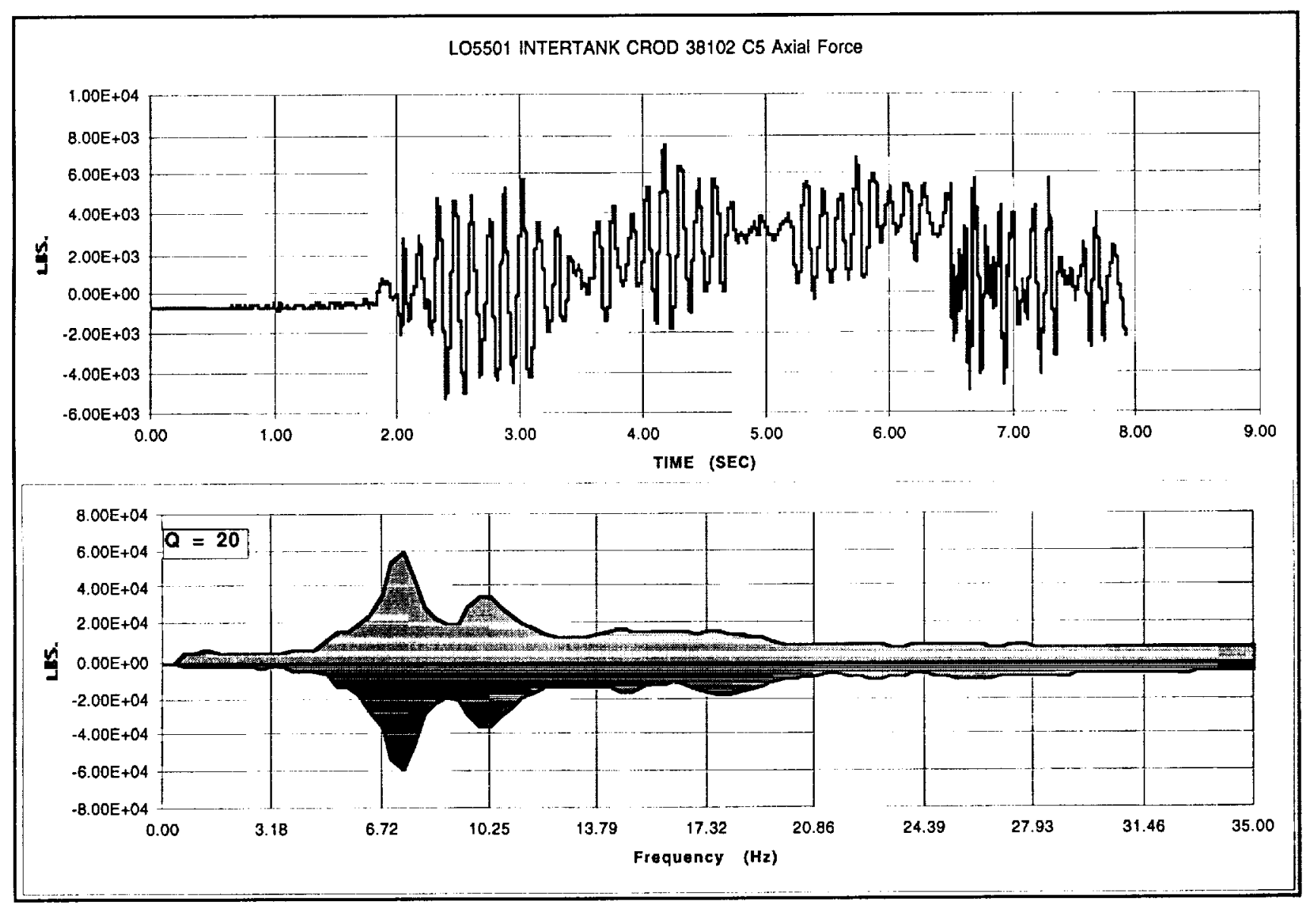

Figure 12, Sample time history results 